\title{
Resection of a Dumbbell Skull Base Meningioma by a Combined Two-Staged Retrosigmoid and Transzygomatic Transcavernous Approach
}

\author{
Álvaro Campero ${ }^{1}$ Leoncio Tovar ${ }^{2}$ Pablo Ajler $^{3}$ \\ ${ }^{1}$ Department of Neurological Surgery, Hospital Padilla, Buenos Aires, \\ Argentina \\ 2 Department of Neurological Surgery, Hospital General de Mexico, \\ México, Mexico \\ ${ }^{3}$ Department of Neurological Surgery, Italian Hospital, Buenos Aires, \\ Argentina
}

\begin{abstract}
Address for correspondence Leoncio Alberto Tovar, Department of Neurological Surgery, Hospital General de México, Balmis 148, Mexico
\end{abstract} 06726, Mexico (e-mail: toroleal@gmail.com).

J Neurol Surg B 2019;80(suppl S3):S298-S299.

This case describes a 32-year-old male with 2 months of headache accompanied with slight right-hand hemiparesis. During a physical examination, he was also detected left facial hypoesthesia. An enhanced magnetic resonance imaging (MRI) showed a large size lesion on the region of the left cerebellopontine angle, with large displacement of the brainstem and cerebellum. The tumor extended to the cavum of Meckel, displacing and pushing the left cavernous sinus upward. After analyzing the anatomical characteristics of the tumor, surgery was decided in two steps. Since the symptoms were mostly produced by the tumor part located in the posterior fossa, a decision was made to first resect that part of the tumor. With the patient in a semisitting position, we performed a left retrosigmoid craniotomy, exposing the transverse and sigmoid sinus edges. Using microsurgical technique, and ultrasonic aspirator, the complete removal of the lesion located in the posterior fossa was achieved. The patient presented a very good postoperative period, without a new neurological deficit. A month after the surgery, the patient no longer suffered from headaches or hemiparesis, but continued the left facial hypoesthesia. The pathology reported clear cell meningioma. Another month later, a transcygomatic approach plus peeling of the cavernous sinus was performed with the patient in the supine position and head rotated to the right side. Spinal drainage was previously placed. The total resection of the tumor was achieved without any surgical complication. The patient presented an excellent postoperative condition without new neurological deficit. The pathologist confirmed the diagnosis of clear cell meningioma.

The link to the Video can be found at: https://youtu.be/SmRy5HiJYJI.
Conflict of Interest

None.

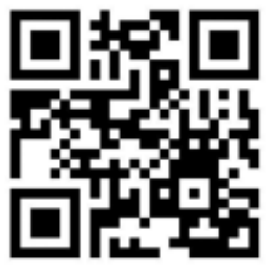

received

April 16, 2018

accepted after revision

August 19, 2018

published online

November 21, 2018

www.thieme.com/skullbasevideos

www.thieme.com/jnlsbvideos

DOI https://doi.org/

10.1055/s-0038-1675173. ISSN 2193-6331. (c) 2019 Georg Thieme Verlag KG Stuttgart · New York
License terms

(c) (i) $\ominus \circledast$ 


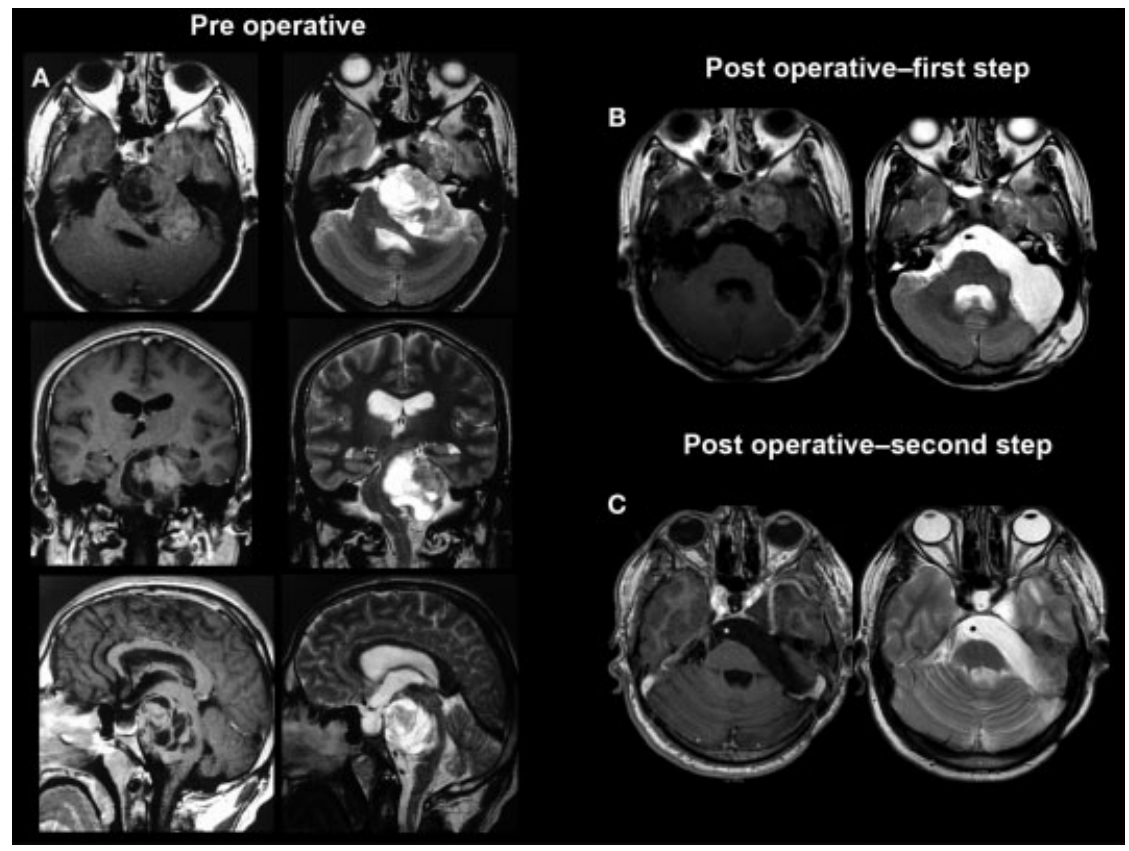

Fig. 1 (A) Axial, coronal, and sagittal preoperative images in enhanced T1 and T2 sequences, showing a well-defined lesion located in the left cerebellopontine angle and left cavernous sinus. (B) Postoperative axial images after resection of the lesion in the posterior fossa. (C) Postoperative axial images after resection of the tumor in the cavernous sinus.

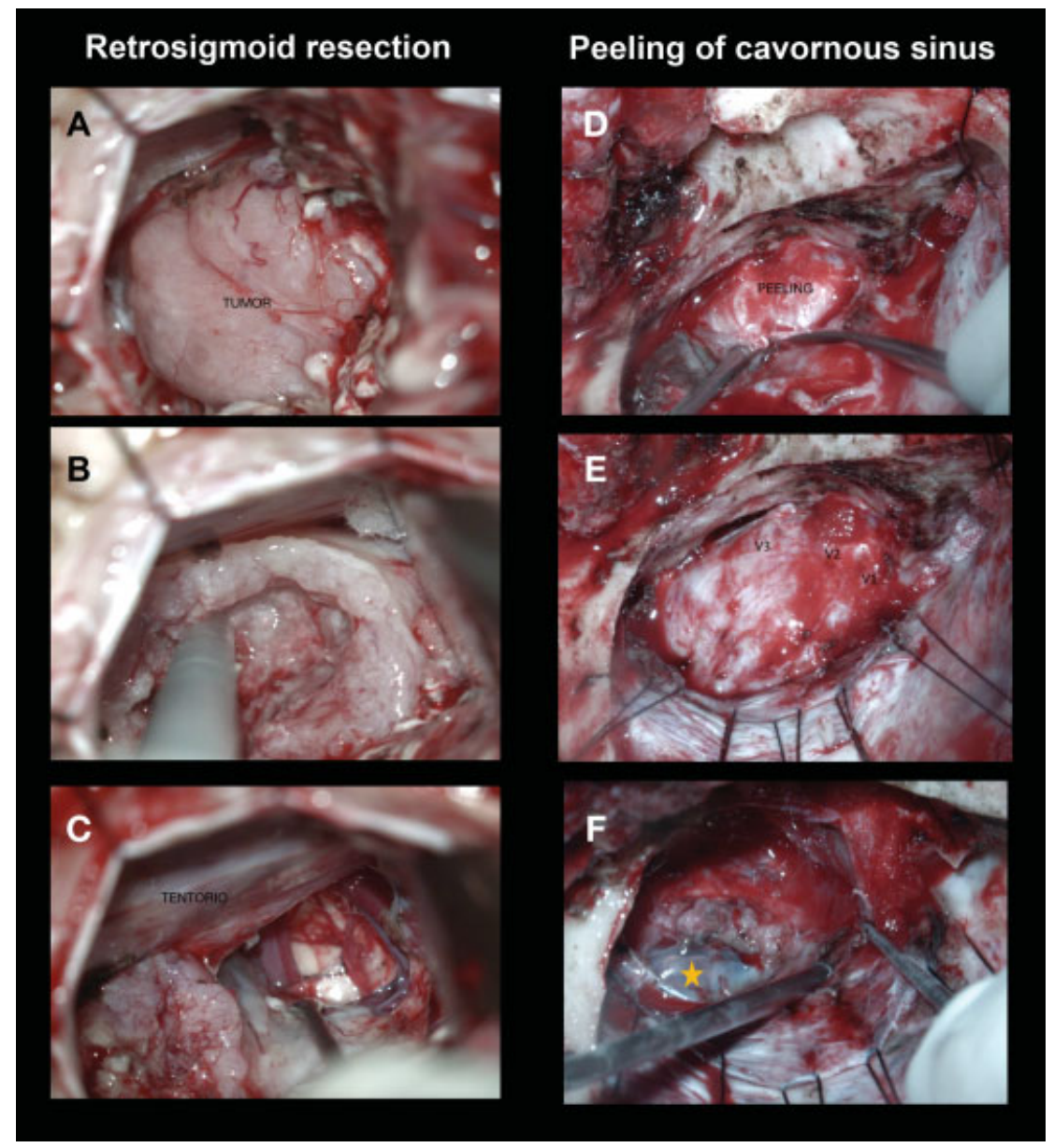

Fig. 2 (A, B, and C) Intraoperative images of the first surgical time, demonstrating features of the tumor and the surgical technique. $(\mathrm{D}, \mathrm{E}$, and $\mathrm{F}$ ) The peeling of the cavernous sinus, and the relation of the tumor with the trigeminal nerve. 